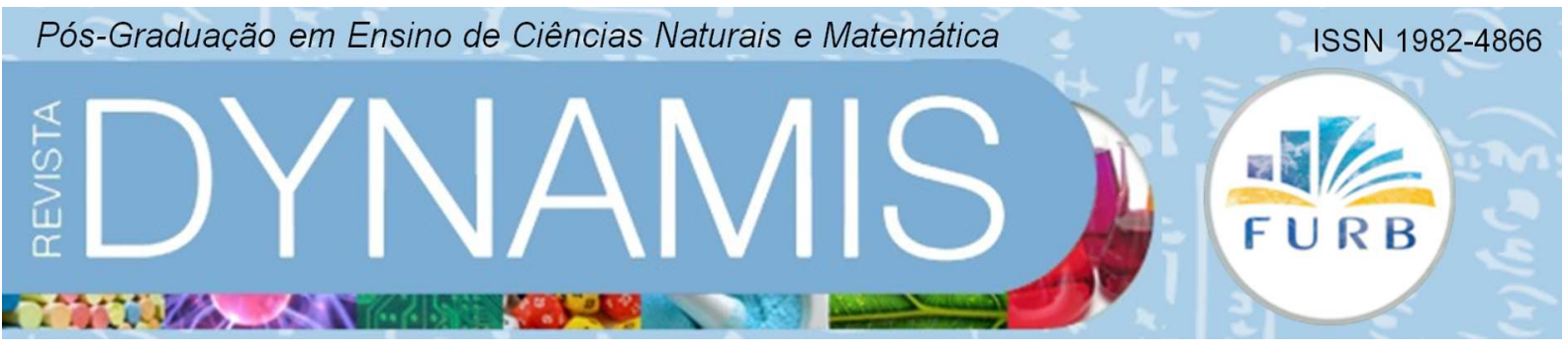

\title{
EXPLORANDO A IDEIA DE ACASO NOS FENÔMENOS ALEATÓRIOS, A PARTIR DE UMA SEQUÊNCIA DE ENSINO
}

Exploiting the idea of chance in random events, from a teaching sequence

Saulo Vargas

Instituto Federal de Educação, Ciência e Tecnologia de Santa Catarina - IFS

vargassaulo@gmail.com

Geraldo Moretto

Programa de Pós-graduação em Ensino de Ciências Naturais e Matemática - PPGECIM/FURB Universidade Regional de Blumenau

gmoretto@furb.br 


\title{
Resumo
}

Este artigo apresenta os resultados de uma pesquisa de mestrado, e seu objetivo é mostrar uma sequência de ensino que explore a ideia de acaso nos fenômenos aleatórios. Essa sequência de ensino é constituída de um questionário aberto para investigar como os alunos consideram o acaso nos eventos aleatórios e de quatro atividades para explorar a ideia de acaso em experimentos aleatórios. A sequência foi aplicada com alunos dos cursos superiores de Biologia e Medicina Veterinária. Com base nos resultados da sequência de ensino, constatou-se que houve uma melhora significativa na concepção dos alunos de como consideram o acaso nos fenômenos aleatórios.

Palavras-chave: Ensino. Aprendizagem da Probabilidade e Estatística. Sequência de Ensino. Acaso.

\begin{abstract}
This paper presentes the results of a research of master's, and your objective is to show a teaching sequence that explores the ideia of chance in randon phenomena. This teaching sequence consists of an open questionnaire to investigate how students consider the chance in random events and of four activities to explore the idea of chance in random experiments. The sequence was applied with students of higher education courses in Biology and Veterinary Medicine. Based on the results of the teaching sequence, concluded that there was a significant improvement in the conception of the studies of how consider the chance in randon phenomena.
\end{abstract}

Keywords: Teaching. Learning. Probability and Statistics. Teaching Sequence. Chance. 


\section{INTRODUÇÃO}

Diversas áreas de estudo, como ciências da saúde, ciências sociais, ciências tecnológicas e ciências humanas, utilizam conceitos de probabilidade e estatística para justificar os resultados de suas pesquisas. Nessas situações em que os julgamentos são baseados em probabilidades, deve-se sempre considerar o acaso para que não ocorram surpresas indesejáveis na decisão tomada. Não é porque um evento aleatório tem baixa probabilidade, que ele não pode ocorrer, ou porque tem alta probabilidade, que certamente ocorrerá.

Devido à grande importância da probabilidade e estatística para a fundamentação dos resultados de pesquisas em várias áreas de estudo, seu ensino deve explorar a consideração do acaso nos resultados de eventos aleatórios para um ensino mais reflexivo dessa disciplina nos cursos superiores, corroborando para a formação de estudantes que possam tomar decisões mais conscientes e compreender melhor as oscilações dos fenômenos aleatórios do mundo em que atuam.

Entretanto, se por um lado é reconhecida a importância da probabilidade e estatística para diversas áreas, por outro, pesquisas em educação evidenciam uma situação preocupante no que tange ao ensino dessa disciplina.

Pesquisas apontam que alunos apresentam concepções errôneas ou dificuldades em resolver situações que trabalham com o acaso, mesmo após estudarem conceitos de probabilidade e estatística (TVERSKY, KAHNEMAN, 1971; COUTINHO, 1994; FIGUEIREDO, 2000; SEBASTIANI, VIALI, 2011). Esses autores também constataram que muitas das dificuldades detectadas estão relacionadas com a metodologia adotada pelos professores que valorizam o conhecimento formal, desvinculado da realidade ou com uma linguagem inacessível ao aluno, e/ou uma abordagem meramente algorítmica.

Considerando esse cenário, este artigo apresenta os resultados de uma pesquisa de mestrado sobre a importância de considerar o acaso nos fenômenos aleatórios, e seu objetivo é mostrar uma sequência de ensino que explore a ideia de acaso nos fenômenos aleatórios, visando auxiliar professores e alunos no processo de ensino e aprendizagem de conceitos de probabilidade e estatística.

\section{A NOÇÃO DE ACASO}

Todos nós já tivemos, de alguma forma, a influência das leis do acaso nos resultados de nossas experiências. Seja em uma partida de dominó, um jogo de cartas, ou até mesmo no tradicional jogo de moedas "cara-ou-coroa" para ver quem inicia uma partida de futebol de botão, por exemplo.

Essas experiências, em que não nos parece possível prever o que vai acontecer, são experiências aleatórias, seus resultados são determinados ao acaso. Contudo, as pedras recebidas numa partida de dominó ou a face visível da moeda podem ser perfeitamente determinadas, dependendo da maneira como elas são distribuídas ou lançadas. Mas é importante ressaltar, que excluindo as possibilidades de trapaça ou ingenuidade humana, as ínfimas variações, impossíveis de controlar em uma experiência, é que a torna aleatória.

Bennett (2003, p.9) coloca que "quando o acaso determina o resultado, nenhuma quantidade de inteligência, habilidade, força, conhecimento ou experiência pode dar vantagem a um único jogador, e a "sorte' surge como uma força equalizadora". A expressão "sorte", 
destacada por Bennett, é entendida aqui como algo desconhecido ou sobrenatural que influencia no resultado.

Desta forma, sem cometer o paradoxo da linguagem ${ }^{1}$, podemos afirmar que o acaso é a falta de conhecimento da causa, é fruto de nossa ignorância. Como não sabemos o que influenciou tal resultado, atribuímos o fato ocorrido ao acaso. Essa visão que damos ao acaso também é reforçada nas palavras de Lestienne (1899, p.23), que aborda o acaso como sendo "o véu com o qual recobrimos nossa ignorância em relação às causas dos acontecimentos, sem que coloquemos em dúvida a existência dessas causas".

O relacionamento da humanidade com essa ideia de acaso existe desde a antiguidade. Os povos primitivos acreditavam que o acaso era uma forma justa de determinar os movimentos dos jogos e de algumas situações da vida real. Para isso, recorriam a aleatorizadores com o intuito de obter orientação divina ou em jogos, pois não conheciam as causas que levariam aos resultados do aleatorizador, atribuindo-as aos deuses (BENNETT, 2003).

\section{ESTRATÉGIAS DE ENSINO}

No âmbito dos desafios, exigências e possibilidades da ação docente, de acordo com Furtado et al. (2007), o processo de ensino e aprendizagem precisa de um planejamento educacional que contemple estratégias de ensino que contribuam com o desenvolvimento cognitivo do aluno.

O uso de estratégias de ensino é uma maneira de inserir os alunos em novos contextos, mas, para isso, as atividades devem levar em conta o conhecimento prévio dos alunos, estimular a ação dos alunos na construção de suas concepções, assegurar a interação entre alunos e incentivar a investigação para desenvolver a autonomia dos alunos (LIBANẾO, 1994).

Saber que concepções os alunos trazem sobre um tema a ser explorado pode auxiliar o processo de ensino e aprendizagem de qualquer ciência, pois "a aprendizagem da ciência é um processo de desenvolvimento progressivo do senso comum. Só podemos ensinar e aprender partindo do senso comum que o aprendiz dispõe." (ALVES, 1985, p.12). Todos os alunos trazem contribuições e carregam uma bagagem que deve ser (re)conhecida, nesse processo, pelo professor, cabendo a ele desenvolver e aplicar recursos que captem o conhecimento prévio do aluno acerca do assunto a ser estudado.

A aplicação de um questionário é uma maneira simples de conhecer o entendimento que o aluno tem sobre determinado objeto de estudo e de envolvê-lo na construção do seu próprio conhecimento. Hill (2005, p.94) coloca que um "questionário que contenha apenas perguntas abertas é essencialmente útil quando se pretende realizar um estudo preliminar para encontrar variáveis importantes ou relevantes, não localizadas na literatura.".

Uma forma de provocar nos alunos processos cognitivos que lhes desafiem a tomar, decisões, resolver problemas e refletir, passa pela aplicação de recursos didáticos que complementam a ação do professor e facilitam o processo de ensino e aprendizagem do objeto em questão. Pais (2000), afirma que:

\footnotetext{
1 "Paradoxo da linguagem: como dar a uma palavra um sentido novo sem utilizar essa mesma palavra?" (GONSETH apud BOURSIN, 1974, p.40)
} 


\begin{abstract}
Os recursos didáticos envolvem uma diversidade de elementos utilizados como suporte experimental na organização do processo de ensino e de aprendizagem. Sua finalidade é servir de interface mediadora para facilitar na relação entre professor, aluno e o conhecimento em um momento preciso da elaboração do saber. [...] São criações pedagógicas desenvolvidas para facilitar o processo de aquisição do conhecimento.
\end{abstract}

Libâneo (1994) aponta que as estratégias de ensino colaboram para o desenvolvimento das capacidades cognoscitivas, como: observação, percepção, compreensão, raciocínio, memória, linguagem, conhecimentos já disponíveis, linguagem, etc., quando estimulam a atividade mental dos alunos, de modo que aprendam os conteúdos escolares e saibam usá-los em novas situações.

Em um mapeamento das dissertações do Programa Estudos Pós-Graduados em Educação Matemática da PUC-SP produzidas de 1994 a 2006, acerca do ensino e aprendizagem da probabilidade e estatística, Oliveira (2007) constatou que as pesquisas utilizaram como estratégia de ensino, a elaboração e aplicação de uma sequência didática, atividade diagnóstica ou questionário, a fim de promover uma ensino mais reflexivo. Segundo Oliveira, os autores pesquisados conseguiram atingir o objetivo proposto em suas pesquisas, mesmo que alguns parcialmente.

O uso de estratégias de ensino não garante uma aprendizagem efetiva de todos os alunos, mas possibilita desenvolver contextos possíveis para que de fato ocorra interação entre professor, alunos e objeto de estudo. A escolha de estratégias de ensino apropriadas aos objetivos, conteúdos e ao grupo de alunos, constitui um dos passos fundamentais para a eficiência do processo de ensino aprendizagem (FURTADO et al, 2007)

\title{
4 METODOLOGIA
}

Optou-se como alternativa metodológica pelo desenvolvimento de uma sequência de ensino para auxiliar no processo de ensino e aprendizagem da disciplina probabilidade e estatística, no que tange a consideração do acaso nos fenômenos aleatórios.

Esta sequência de ensino foi aplicada a um total de 45 alunos dos cursos de Biologia e Medicina Veterinária, que cursavam a disciplina Estatística Aplicada e Bioestatística II, respectivamente. A escolha desses cursos se deu pela acessibilidade e por suas matrizes curriculares contemplarem disciplinas voltadas ao ensino da probabilidade e estatística.

Essa sequência de ensino divide-se em duas etapas: $1^{\text {a }}$ - aplicação de um questionário aberto para verificar como os alunos consideram o acaso nos fenômenos aleatórios; $2^{\mathrm{a}}$ - aplicação de atividades didáticas para consideração do acaso.

As perguntas do questionário aberto foram baseadas em elementos de probabilidade $\mathrm{e}$ estatística (Eventos pouco prováveis; Lei dos grandes números; Testes de hipótese) e exigiam, em suas respostas, fragmentos do não causal. A aplicação do questionário ocorreu individualmente durante uma aula de 50 minutos

As atividades foram elaboradas levando em conta as concepções de como os alunos consideraram o acaso nos fenômenos aleatórios, após a aplicação da primeira etapa. Para a aplicação das experiências, foram utilizadas duas aulas geminadas de 50 minutos cada, e as atividades foram aplicadas em grupos de 3 alunos. 
A análise dos dados foi realizada com base nas respostas apresentadas ao questionário e nos relatórios das atividades didáticas.

A descrição na íntegra do questionário e das atividades está disponível no produto educacional postado no endereço eletrônico: http:// , após acessar o site clique no link "Acervo Digital” e faça a consulta pelo nome do autor.

\section{RESULTADOS E DISCUSSÃO}

Após a apresentação da proposta de trabalho, que possibilitou aos alunos conhecerem o motivo da intervenção, foi iniciada a sequência de ensino com a aplicação do questionário aberto. Com base nas respostas dadas ao questionário, foram identificadas três concepções de como esses alunos consideram o acaso no resultado dos eventos aleatórios, a partir de como inseriram o não causal em suas respostas.

$1^{\text {a) }}$ Consideram o acaso e o utilizam corretamente em suas justificativas. Essa concepção mostra que esses alunos compreendem que não é possível conhecer as causas que influenciam na ocorrência do resultado de um evento aleatório, e apresentam esse fato nas justificativas de suas respostas.

Para ilustrar essa primeira concepção, serão reproduzidas algumas respostas apresentadas a uma das perguntas que trata da ocorrência de eventos pouco prováveis. Nessa pergunta, os alunos tinham que responder e justificar se é possível ocorrer os mesmos resultados em 10 lançamentos de uma moeda honesta e 10 de uma moeda viciada.

\footnotetext{
Questionário 02. Sim, porque na moeda honesta pode cair qualquer face e coincidentemente pode ser a mesma face da moeda viciada.

Questionário 32. Sim, mas a probabilidade é pequena.

Questionário 45. Sim a chance é pequena, mas pode ocorrer da moeda honesta cair 10 vezes do mesmo lado.
}

Apesar de algumas respostas não usarem explicitamente a expressão "ao acaso", foram consideradas, para classificação nessa concepção, expressões que remetem ao não causal como: raridade, baixa probabilidade, chance pequena, ou podem ocorrer os mesmos resultados. Essas expressões dão indícios de que os alunos justificaram a ocorrência do evento pouco provável como algo que pode acontecer porque não se conhecem as causas que levaram a tal evento.

$2^{\text {a }) ~ C o n s i d e r a m ~ o ~ a c a s o, ~ m a s ~ n a ̃ o ~ o ~ u t i l i z a m ~(c o r r e t a m e n t e) ~ e m ~ s u a s ~ j u s t i f i c a t i v a s . ~}$ Essa segunda concepção mostra que esses alunos também compreendem que não é possível conhecer as causas que influenciam na ocorrência do resultado de um evento aleatório, mas não apresentam esse fato nas justificativas de suas respostas.

Ao observarmos as respostas apresentadas a pergunta referente a testes de hipóteses, percebemos que alguns alunos não consideram que os resultados encontrados em uma amostra obtida ao acaso possam ser extrapolados à população, pois pode ser que a amostra não tenha o número mínimo de elementos.

Questionário 33. Talvez, se a amostra for pequena não, porque vão ser poucos indivíduos. 
Questionário 14. Depende do tamanho da amostra. Quanto maior for a amostra maior a probabilidade desse resultado ser o mesmo de toda a população.

Questionário 02. Não, porque para se chegar a uma conclusão ele deve pegar uma amostra de grande número de indivíduos e os mais variados possíveis. E também quem garante que os dados que ele obteve são confiáveis.

A justificativa apresentada pelos alunos é interessante e deve realmente ser considerada na avaliação de uma conclusão, uma amostra com poucos elementos quase sempre não garantirá resultados confiáveis. Porém, esse grupo não considerou a aleatoriedade da amostra, visto que, mesmo com um número mínimo de elementos (ou grande como colocam alguns alunos), pode ser que somente aquela amostra apresente determinado resultado.

$3^{a}$ ) Não consideram o acaso. Essa última concepção mostra que esses alunos compreendem que é possível conhecer as causas que influenciam na ocorrência do resultado de um evento aleatório.

$\mathrm{Na}$ respostas dadas a pergunta referente a lei dos grandes números, alguns alunos responderam que é mais provável que ocorram os mesmos resultados em 100 do que em 10 lançamentos de duas moedas, uma honesta e outra viciada.

Questionário 45. Em 100, porque tem mais jogadas para acertar.

Questionário 34. Em 100, quanto mais lançamentos maior a chance.

Questionário 02. Em 100, porque quanto mais lançamentos se fizer mais chance se tem de chegar a um resultado em comum.

Observa-se, nessas respostas, que os aluno consideraram que quanto maior o número de lançamentos, maiores são as chances de ocorrerem resultados iguais, o que é um equívoco, pois quanto maior o número de lançamentos, mais próximas das suas probabilidades teóricas estarão essas duas moedas de probabilidades teóricas diferentes e menores serão as chances de ocorrerem os mesmos resultados.

Analisando as respostas de todos os alunos, constatou-se que nenhum aluno apresentou concepção unânime, dentre as três destacadas. Percebeu-se que os alunos, mesmo cursando, no momento da aplicação do questionário, uma disciplina que aborda conceitos de probabilidade e estatística, apresentam concepções confusas quando fazem julgamentos dos resultados dos eventos aleatórios.

As divergências encontradas em relação a como consideram o acaso nos fenômenos aleatórios demonstram que os alunos apresentam concepções que podem se tornar obstáculos à aprendizagem de conteúdos que necessitem da compreensão do não casual. Coutinho (1994) argumenta que a dificuldade na resolução de questões que envolve caráter subjetivo reforçam as concepções errôneas dos alunos, quando não trabalhadas adequadamente.

Essas concepções errôneas da consideração do acaso nos fenômenos aleatórios podem ser dirimidas quando o professor as identifica e as considera no desenvolvimento do seu trabalhado, envolvendo os alunos em situações ou atividades que estimulem o pensamento crítico. 
Dentro dessa perspectiva, foram construídas e aplicadas atividades didáticas levando em conta as concepções que os alunos apresentaram e visando a auxiliar na consideração do acaso por meio de experiências que introduzem conceitos de probabilidade e estatística e explorem fatores casuais.

As atividades propostas foram aplicadas em grupos para que os alunos pudessem colocar em discussão as hipóteses levantadas e criar argumentos consistentes de acordo com seus níveis de entendimento. A seguir são reproduzidos alguns relatos das atividades didáticas.

Ao repetirem várias vezes quatro lançamentos de uma moeda honesta e de outra viciada, os grupos constataram que devido o resultado se dar ao acaso, experimentos com moedas honestas podem ter os mesmos resultados de experimentos com moedas viciadas.

\footnotetext{
Relatório 02: Sim. Por causa do acaso, não tendo como prever.

Relatório 03: Sim aconteceu, pois apesar de uma moeda ser honesta e outra ser viciada, os resultados foram ao acaso.
}

Relatório 04: Existem vários resultados com a mesma proporção de caras e coroas e isso se deve ao acaso.

Ao observarem a proporção total de uma das faces nesses experimentos do lançamento das moedas honesta e viciada, todos os grupos relataram que as proporções foram diferentes, pois realmente não encontraram proporções iguais nos dois experimentos. Os grupos argumentaram que esse resultado se deve ao fato de uma das moedas ser viciada. Conforme se percebe nos relatórios seguintes:

Relatório 04: É diferente e isso pode ser, pois no segundo experimento a moeda é viciada.

Relatório 05: Diferente. Devido a segunda moeda ser viciada.

Relatório 06: É diferente, pois a moeda viciada tem maior probabilidade de cair na face viciada.

Relatório 08: A diferença ocorreu por uma das moedas estar viciada.

Nas atividades relacionadas a testes de hipótese, os alunos também consideraram o acaso nas justificativas dos questionamentos apresentados. Em uma das atividades, os alunos constataram que testes de hipótese realizados com amostras distintas, obtidas ao acaso, da mesma população, podem apresentar resultados diferentes, devido à aleatoriedade na seleção da amostra. Conforme se percebe nos relatórios a seguir:

Relatório 02: São diferentes, porque a seleção das amostras foi ao acaso.

Relatório 03: Os resultados foram diferentes. Na nossa amostra $\mathrm{H}_{0}$ foi rejeitado, já na outra equipe foi aceito $H_{0}$. Essa diferença é devido a seleção da amostra que ocorreu ao acaso, fazendo com que nosso resultado se distanciasse da média.

Relatório 07: Uma equipe rejeitou e 4 aceitaram que não há diferença, isso ocorreu pela aleatoriedade na seleção da amostra.

Relatório 08: São diferentes, pois há a possibilidade de dar qualquer resultado devido a amostra ter sido obtida ao acaso. 
Nessa atividade, os alunos compararam vários resultados de testes de hipótese realizados com o mesmo nível de significância e com amostras de mesmo tamanho, obtidas ao acaso, e perceberam que testes de hipótese não são $100 \%$ confiáveis, pois podem apresentar resultados diferentes.

Com base nos relatórios das atividades didáticas, constatou-se que essas auxiliaram os alunos a considerar o acaso no resultado dos fenômenos aleatórios, pois os alunos o utilizaram corretamente como justificativa para os questionamentos. Isso nos permite dizer que as atividades propostas permitiram aos alunos examinar que não é possível conhecer as causas que influenciam na ocorrência de um determinado fenômeno aleatório.

Além de servir como um elemento de motivacional, as atividades permitiram aos alunos conhecer melhor as particularidades (o que é, como funciona, para que serve) e terminologias de alguns elementos da probabilidade e estatística. Libanêo (1994, p.151), argumenta que as atividades didáticas buscam as "relações internas de um objeto, de um fenômeno, de um problema, uma vez que esse objeto de estudo fornece as pistas, o caminho para conhecêlo".

\section{CONSIDERAÇÕES FINAIS}

Este trabalho teve como objetivo apresentar uma sequência de ensino que explore a ideia de acaso nos eventos aleatórios. Seu propósito não é mostrar uma receita de como explorar a ideia de acaso em sala de aula, mas sim compartilhar estratégias de ensino que visem a auxiliar os professores no processo de ensino e aprendizagem da probabilidade e estatística.

A aplicação do questionário é um ponto de partida para o professor avaliar as concepções dos alunos de como consideram os acaso nos eventos aleatórios e, a partir do resultado obtido, direcionar os questionamentos das atividades propostas para uma aprendizagem reflexiva da probabilidade e estatística.

No caso específico da sequência de ensino aplicada nas turmas de Biologia e Medicina Veterinária, podemos comparar o resultado obtido da aplicação do questionário aberto com o resultado das atividades propostas e constatar, subjetivamente, que houve uma melhora significativa na concepção dos alunos de como consideram o acaso nos eventos aleatórios.

Além de explorar a ideia de acaso nos eventos aleatórios, essa sequência de ensino pode ser utilizada também para explorar as especificidades dos conteúdos de probabilidade e estatística envolvidos na sequência.

\section{REFERÊNCIAS}

ALVES, Rubem. Filosofia da ciência. 6 ed. São Paulo: Brasiliense, 1985.

COUTINHO, Cileda de Queiroz e Silva. Introdução ao conceito de probabilidade por uma visão frequentista. 1994. Dissertação (Mestrado em Matemática) - Pontifícia Universidade Católica de São Paulo, São Paulo, 1994.

FIGUEIREDO, Auriluci de Carvalho. Probabilidade condicional: um enfoque de seu ensino aprendizagem. 2000. Dissertação (Mestrado em Educação Matemática) - Pontifícia Universidade Católica de São Paulo, São Paulo, 2000. 
FURTADO, Clara Maria et al. Docência no ensino superior: metodologias educacionais. Blumenau: Nova Letra, 2007.

HILL, Manuela Magalhães; HILL, Andrew. Investigação por questionário. 2. ed. Lisboa: Silabo, 2005. p. 69-166.

LESTIENNE, Rémy. O acaso criador. Tradução de Adriana Rizzo Garcia e Mary Amazonas Leite de Barros. São Paulo: Edusp, 2008.

LIBANÊO, José Carlos. Didática. São Paulo: Cortez, 1994.

SEBASTIANI, Renate Grings; VIALI, Lori. Testes de hipótese: uma análise dos erros cometidos por alunos de engenharia. Bolema, Rio Claro, v. 24, n. 40, p. 835-854, dez. 2011. Disponível em: <http://www.periodicos.rc.biblioteca.unesp.br/index.php/bolema/issue/view/863>. Acesso em: 13 fev. 2012.

TVERSKY, Amos, KAHNEMAN, Daniel. Belief in the law of small numbers. Psychological Bulletin, Washington. 76, n. 2, p. 105-110, ago. 1971. Disponível em: <http://psycnet.apa.org/journals/bul/76/2/>. Acesso em: 15 dez. 2011. 